\title{
EL DERECHO DE ORIGEN INTERNACIONAL EN LA INTERPRETACIÓN CONSTITUCIONAL DE LA SUPREMA CORTE DE JUSTICIA DE LA NACIÓN
}

Karlos CASTILLA

Aun cuando parezca extraño, es cada vez más común encontrar en las sentencias que emite la Suprema Corte de Justicia de la Nación referencias al derecho de origen internacional y las interpretaciones que de éste se han hecho. Esto se hace principalmente como una forma de reforzar la argumentación, pero también cada vez más como una manera de nutrir el contenido de las normas constitucionales y, tal vez, como un incipiente intento del llamado control de convencionalidad o aplicación acorde a tratados.

Se ha pasado de la simple cita o mención que se hacía de artículos contenidos en tratados de derechos humanos a la construcción de argumentos con el apoyo de criterios emitidos por órganos internacionales.

Lo anterior es un aspecto digno de destacar, ya que si se revisan las sentencias de tribunales mexicanos, al menos de los últimos diez años, era muy difícil encontrar en el contenido éstas referencias de tratados internacionales en materia de derechos humanos y menos aún de las interpretaciones que respecto a éstos han dado los órganos internacionales de protección de los derechos humanos. Algunos tribunales colegiados de circuito y el Tribunal Electoral del Poder Judicial de la Federación muestran algunos avances, aunque no todos acertados. Pero en el ámbito local sigue siendo prácticamente nulo este trabajo.

En ese sentido y con el fin de dar orden al debate que se hace respecto a estos temas, a continuación, analizaremos de manera general los avances que en la Suprema Corte de Justicia de la Nación se han dado en la incorporación de estándares internacionales para la interpretación cons- 
titucional, así como la manera en que se ha recogido la jurisprudencia de órganos internacionales de protección de los derechos humanos cuando se invocan los tratados de este tipo. No dudamos que otros órganos tengan ya importantes avances, pero por ahora nos interesa destacar qué pasos ha dado nuestro máximo tribunal en este sentido.

Cabe destacar que sólo señalaremos los asuntos en los cuales se ha hecho, cuál es el órgano internacional al que se acude y para qué se utiliza el derecho de origen internacional o la jurisprudencia internacional. El propósito en este momento sólo es hacer un recuento de los casos en los que se ha llevado a cabo algo más que la cita de artículos de instrumentos internacionales. Por ahora no analizaremos si la forma en la que se hizo fue correcta o no, sino en dónde se encuentra y con qué propósito. Lo que ahí encontraremos, a muchos les podrá parecer un esfuerzo desafortunado, pero debe evaluarse en su justa dimensión y teniendo en cuenta el lugar que en el pasado reciente ha ocupado el derecho de origen internacional en la Suprema Corte de México.

Desde esa perspectiva, las sentencias que hasta hoy se destacan son las siguientes.

\section{ACCIONES DE INCONSTITUCIONALIDAD}

\section{45/2006 y su acumulada 46/2006}

Por medio de esta acción de inconstitucionalidad el Partido Acción Nacional y el Partido Convergencia solicitaron la invalidez de los artícu$\operatorname{los} 19,37,45,47,53,54,55,70,71,81,82,115,116,119,129,243$ у 244 de la Ley Electoral del Estado de Zacatecas; 13, párrafo segundo; 23, fracción XLII; 65, fracción VI; y 72-A de la Ley Orgánica del Instituto Electoral del Estado de Zacatecas y de otras disposiciones del mismo estado, porque consideraban, entre otras cosas, que una de las normas legales referidas no respetaba la libertad de expresión y la prohibición de censura previa anticipadas en la Constitución Federal.

Para determinar lo anterior, en la sentencia se acude a lo establecido en el artículo 13 de la Convención Americana sobre Derechos Humanos, así como al artículo 19 del Pacto Internacional de Derechos Civiles y Políticos. De igual manera se observa lo que la Corte Interamericana de 
Derechos Humanos estableció en la opinión consultiva OC-5/85 y en el caso Olmedo Bustos y otros ("La última tentación de Cristo").

\section{2. $37 / 2006$}

Este medio de control de constitucionalidad fue promovido por la Comisión Estatal de Derechos Humanos de San Luis Potosí, el cual fue uno de los primeros casos en que estos órganos nacionales de protección de los derechos humanos promueven este medio tras la reforma al artículo 105, fracción II, de la Constitución en 2006. Se impulsó en contra de los artículos 1o., fracción I, 4o., 26, 52, 117 y 119 de la Ley de Justicia para Menores del Estado de San Luis Potosí, porque se consideraba que éstos eran contrarios a lo establecido en los artículos 14, 16 y 18 de la Constitución Federal.

En el considerando quinto de esa sentencia, y con el fin de establecer si el sistema de justicia para menores que establecía la ley impugnada era conforme con la Constitución, se incorporan instrumentos de origen internacional como la Convención sobre Derechos del Niño, las Reglas de Beijing, las Reglas de las Naciones Unidas para la Protección de los Niños Privados de Libertad, las Directrices de RIAD, la Resolución 45/115 de la Asamblea General de la Organización de las Naciones Unidas, relativa a la utilización de niños como instrumentos para actividades delictivas, y el inciso f) del párrafo $\mathrm{V}$ del artículo 3o. de la Convención de las Naciones Unidas contra el Tráfico Ilícito de Estupefacientes y Sustancias Psicotrópicas.

Asimismo, se utilizan criterios establecidos por el Comité de Derechos del Niño de Naciones Unidas en cuanto a los alcances y las obligaciones que tienen los Estados para la protección de los niños, y lo establecido por la Corte Interamericana de Derechos Humanos en su opinión consultiva OC-17/02 "Condición jurídica y derechos humanos del niño", para establecer las líneas generales de protección con las que deben contar los menores de edad ante los órganos de administración de justicia.

Además de lo antes señalado, se destaca que en ese asunto la Suprema Corte estableció en correspondencia con lo dicho por la Corte Interamericana respecto de su jurisprudencia derivada de opiniones consultivas que: 
Esta opinión de la Corte Interamericana no resulta formalmente vinculante, pues, como la propia Corte lo explicó, su función consultiva es la interpretación de esta Convención o de otros tratados concernientes a la protección de los derechos humanos en los Estados americanos, a modo de un servicio que la Corte está en capacidad de prestar a todos los integrantes del sistema interamericano con el propósito de coadyuvar al cumplimiento de sus compromisos internacionales referentes a derechos humanos; no obstante, y precisamente porque interpreta los tratados de derechos humanos que son fuente formal de derecho en México, resulta orientadora para comprender la reforma constitucional al artículo 18, de 2005.

\section{146/2007 y su acumulada 147/2007}

Este medio de control constitucional lo promovió la Comisión Nacional de los Derechos Humanos y la Procuraduría General de la República; ambos solicitaron la invalidez de la reforma a los artículos 144, 145, 146 y 147 del Código Penal para el Distrito Federal, así como la adición de los artículos 16 bis 6, tercer párrafo, y 16 bis 8, último párrafo, a la Ley de Salud para el Distrito Federal .

Para determinar si la interrupción legal del embarazo era o no compatible con la Constitución, la Suprema Corte en la sentencia, entre otras cosas, hace un análisis respecto al derecho a la vida y para ello utiliza el contenido de diversos instrumentos internacionales en materia de derechos humanos como: la Declaración Universal de Derechos Humanos (artículo 3o.), el Pacto Internacional de Derechos Civiles y Políticos (artículo 6o.), la Declaración Americana de los Derechos y Deberes del Hombre (artículo 1o.) y la Convención Americana sobre Derechos Humanos (artículo 4o.). De manera complementaria a éstos señala a la Convención sobre los Derechos del Niño (artículos 6o. y 37), el Segundo Protocolo Facultativo del Pacto Internacional de Derechos Civiles y Políticos destinado a abolir la pena de muerte (artículo 1o.), el Protocolo a la Convención Americana relativo a la abolición de la pena de muerte (artículo 1o.), Código de Conducta para Funcionarios Encargados de hacer Cumplir la Ley (artículo 3o.), Principios Básicos sobre el Empleo de la Fuerza y de las Armas de Fuego por Funcionarios Encargados de hacer Cumplir la Ley (principios 4, 5, 6 y 9), Convenios de Ginebra de 
1949 (artículo 3o. común), Convención para la Prevención y la Sanción del Delito de Genocidio (artículos I y II), Declaración sobre la Protección de todas las Personas contra las Desapariciones Forzadas (artículos 1o. y 2o.), Convención Interamericana sobre Desaparición Forzada de Personas (artículos I y II). De la cita de estos instrumentos obtiene una primera conclusión respecto a que el derecho a la vida no es absoluto, y establece las garantías genéricas y específicas con que cuenta este derecho.

Para respaldar parte de esos argumentos acude a lo establecido por la Corte Interamericana en los casos Los "niños de la calle" (Villagrán Morales y otros, Hilaire, Constantine y Benjamin y otros), así como lo dicho en la opinión consultiva OC-3/83 sobre restricciones a la pena de muerte (artículos 4.2 y 4.4 de la Convención Americana sobre Derechos Humanos). También utiliza lo señalado por el Comité de Derechos Humanos en la observación general número 6 .

Para desarrollar otros aspectos relacionados con establecer que el derecho a la vida no es absoluto y que no hay derechos humanos que se encuentren por encima de otros, así como que hay derechos que se deben respetar bajo cualquier circunstancia, acude a lo establecido en la Declaración de Viena, adoptada por la segunda Conferencia Mundial sobre Derechos Humanos en 1993 y a lo que la Corte Interamericana dijo en el caso Castañeda Gutman.

Otro elemento que deriva del análisis que hace de esos instrumentos y decisiones en materia de derechos humanos es que los mismos no definen el momento en el cual inicia la protección del derecho a la vida, ni desde que momento el ser humano es sujeto de protección. Destaca la Suprema Corte que el único tratado internacional que hace referencia a un momento específico para el inicio de la protección del derecho a la vida es la Convención Americana sobre Derechos Humanos, que establece un momento a partir del cual, "en general", debe ser protegida la vida, y a partir de ello el Máximo Tribunal hace todo un desarrollo respecto al origen de ese artículo acudiendo para ese fin a los trabajos preparatorios de la Convención Americana y a otros documentos, destacando en este aspecto las razones por las cuales no acude a la jurisprudencia de la Corte Interamericana, que si bien versa sobre el derecho a la vida, no era aplicable al caso que analiza .

Posteriormente y para establecer cuando existe la obligación de penalizar conductas, acude a lo establecido en la Convención para la Preven- 
ción y la Sanción del Delito de Genocidio, la Convención Interamericana Sobre Desaparición Forzada de Personas y la Convención Interamericana para Prevenir Sancionar y Erradicar la Violencia contra la Mujer "Convención de Belém Do Pará", como ejemplos en los que derivado de una obligación internacional el Estado debe sancionar determinadas conductas.

En la sentencia también se acude a lo establecido por otros tribunales superiores o constitucionales y se describe como la eliminación de la pena de muerte "obedec[ió] a la existencia de obligaciones en derecho internacional en materia de derechos humanos para ajustarse a la tendencia internacional".

\section{AMPAROS DIRECTOS}

\section{1. $6 / 2008$}

El amparo se interpuso en contra de actos de la Primera Sala Familiar del Tribunal Superior de Justicia del Distrito Federal por estimarlos violatorios de los artículos 1o., 4o., 14 y 16 de la Constitución Política de los Estados Unidos Mexicanos. El caso, relacionado con el tema de cambio de sexo, utiliza jurisprudencia de la Corte Europea de Derechos Humanos como lo es la del caso Christine Goodwin. También acude a decisiones de otros tribunales nacionales y utiliza el contenido de la Declaración Universal de los Derechos Humanos, de la Convención Americana sobre Derechos Humanos, del Pacto de Derechos Civiles y Políticos y del Pacto de Derechos Económicos, Sociales y Culturales, para desarrollar el principio de igualdad, así como para destacar que toda persona humana tiene derecho a la libertad, a la no discriminación, entre otros, por razón de sexo, al reconocimiento de su personalidad jurídica y que nadie podrá ser objeto de injerencias arbitrarias en su vida privada, teniendo el derecho a la protección de la ley contra tales injerencias o ataques.

\section{2. $30 / 2008$}

El amparo se interpuso en contra de actos de la Primera Sala de lo Familiar del Tribunal Superior de Justicia del Distrito Federal. El asunto se refiere a aspectos relacionados con el divorcio y la perdida de la patria 
potestad. Para resolver esto, la Suprema Corte con el fin de establecer la participación que deben tener los menores en procesos de ese tipo acude al derecho de origen internacional, estableciendo la naturaleza misma de los tratados de derechos humanos y las razones por las cuales deben ser aplicados; en específico, la Convención sobre Derechos del Niño, para ello acude a lo establecido por el Comité de Derechos del Niño en su observación general número 5, por la Corte Internacional de Justicia en su opinión consultiva "Reservas a la Convención sobre la Prevención y Sanción del Delito de Genocidio", la Comisión Europea de Derechos Humanos en el caso Austria vs. Italia, así como por la Corte Interamericana en las opiniones consultivas "Otros tratados. Objeto de la función consultiva de la Corte" (artículo 64 de la Convención Americana sobre Derechos Humanos, OC-1/82), y el "Efecto de las reservas sobre la entrada en vigencia de la Convención Americana sobre Derechos Humanos" (OC-2/82); de igual manera en los casos contenciosos del Tribunal Constitucional, de Los "niños de la calle" (Villagrán Morales y otros) y el de la "Masacre de Mapiripán”.

Para establecer de manera concreta la participación que deben tener los menores acude a lo estipulado por el Comité sobre los Derechos del Niño, el Comité de Derechos Humanos en su observación general número 13 , así como lo señalado por la Corte Interamericana de Derechos $\mathrm{Hu}-$ manos en su opinión consultiva "Condición jurídica y derechos humanos del niño" (OC-17/02).

\section{3. $9 / 2008$}

La demanda de amparo se promovió en contra de la sentencia definitiva de 12 de noviembre de 2007, dictada en el toca 251/2007 por el Primer Tribunal Unitario del Vigésimo Circuito, en la que se determinó la plena responsabilidad de los quejosos en la comisión de los delitos de homicidio calificado, lesiones calificadas, portación de arma de fuego sin licencia y de arma de fuego de uso exclusivo del Ejército, Armada y Fuerza Aérea.

El primer tema que se analiza utilizando estándares internacionales en la sentencia es el relativo a la forma en que se debía tratar el caso en razón de que los quejosos en su mayoría eran indígenas. Para ello se observa la Declaración de las Naciones Unidas sobre Pueblos Indígenas, 
el Convenio 169 de la OIT y la Convención Americana sobre Derechos Humanos, así como las resoluciones de la Corte Interamericana en los casos de las comunidades Mayagna (Sumo) Awas Tingni, Sawhoyamaxa, Yakye Axa y del Pueblo Saramaka. Además de elaborarse argumentos importantes para el tratamiento de todo el caso, es interesante que en la sentencia al analizar el texto constitucional y el de los tratados internacionales se llega a la siguiente conclusión en este tema:

Es importante destacar que la fracción VIII, del apartado A, del artículo 2o. de la Constitución es más protectora que el artículo 20 constitucional e incluso más protectora que el artículo 8.2 de la Convención Americana sobre Derechos Humanos al contener expresiones como "en todo tiempo" y "lengua y cultura". Por lo que de acuerdo con los objetivos de un modelo penal garantista y una interpretación pro persona de las disposiciones legales, se puede entender que se aplicará [la primera disposición citada], en tanto que es la más protectora.

Para establecer aspectos relativos al derecho de la honra y dignidad se acude a lo establecido en el artículo 11 de la Convención Americana sobre Derechos Humanos y el 17 del Pacto Internacional de Derechos Civiles y Políticos, así como a los criterios fijados por el Comité de Derechos Humanos en su observación general número 16. Al analizar aspectos relativos y vinculados con la integridad y la libertad personal se utilizan los artículos 5o. de la Declaración Universal de Derechos Humanos, 7o. y 10 del Pacto Internacional de Derechos Civiles y Políticos, así como 5o. y 7o. de la Convención Americana sobre Derechos Humanos, de igual manera que lo dicho por la Corte Interamericana en los caso Loayza Tamayo, Blake, Los "niños de la Calle" y Castañeda Gutman. Del Comité de Derechos Humanos de Naciones Unidas se acude a su observación general número 20 y a los casos Estrella y Quinteros. La Comisión Interamericana es retomada en los casos Mejía y Hermanas González Pérez.

Para establecer aspectos relativos a pruebas, defensa adecuada y otros elementos procesales, en la sentencia se utiliza el contenido del artículo 8 de la Convención Americana sobre Derechos Humanos, así como del artículo 14 del Pacto Internacional de Derechos Civiles y Políticos. 


\section{AMPAROS DIRECTOS EN REVISIÓN}

\section{1. $2019 / 2006$}

El amparo se interpuso en contra de una sentencia dictada por la Sala Regional del Noroeste II del Tribunal Federal de Justicia Fiscal y Administrativa en Ciudad Obregón, Sonora, y se argumentó la inconstitucionalidad del artículo 207, segundo párrafo, del Código Fiscal de la Federación.

En el considerando quinto de esa sentencia la Suprema Corte utiliza lo señalado por la Corte Interamericana de Derechos Humanos en su opinión consultiva OC-9/87, "Garantías judiciales en estados de emergencia (artículos 27.2, 25 y 8 de la Convención Americana sobre Derechos Humanos), para establecer qué se entiende por recurso judicial efectivo y con ello fortalecer su argumentación respecto a la tutela judicial, que era uno de los aspectos que se señalaban como afectados por la norma secundaria impugnada y como fuente central de inconstitucionalidad de dicha norma.

\section{2. $757 / 2007$}

Este amparo se promovió en contra de la sentencia dictada por el Primer Tribunal Unitario en Materia Penal del Primer Circuito y, aunque se determinó su improcedencia, en el considerando cuarto se cita lo establecido por la Corte Interamericana en el caso Castillo Páez respecto a los que se consideran elementos integrantes de la defensa adecuada previstos en el artículo 8o. de la Convención Americana sobre Derechos Humanos y con ello se argumenta por la Suprema Corte las razones que le impiden incluso suplir las deficiencias para lograr la procedencia del recurso intentado.

\section{3. $871 / 2007$}

En el recurso se impugnó la sentencia dictada por la Tercera Sala Penal del Tribunal Superior de Justicia del Distrito Federal y se argumentó que el artículo 224, párrafo primero, fracción VIII, en relación con el 220, párrafo primero, fracción IV, ambos del Código Penal para el Distrito 
Federal, era contrario al principio non bis inidem contemplado en el artículo 23 de la Constitución.

La Suprema Corte acude a lo establecido por la Corte Interamericana de Derechos Humanos en el caso Loayza Tamayo para apoyar los argumentos que había desarrollado en el considerando cuarto de su sentencia a fin de establecer los alcances y el contenido de dicho principio. De manera expresa señala que acude a esta interpretación con el fin de demostrar que "dicho principio constitucional es compatible con lo establecido en la Convención Americana sobre Derechos Humanos...".

\section{4. $1475 / 2007$}

El amparo se interpuso en contra de la sentencia dictada por el Cuarto Tribunal Colegiado en Materia Civil del Primer Circuito, en la que se señaló que el artículo 4.96 del Código Civil del Estado de México era contrario al artículo 14 de la Constitución. En esta sentencia no se cita ninguna jurisprudencia emitida por algún órgano internacional de protección a los derechos humanos, sin embargo, se utiliza el contenido del artículo 9o. de la Convención de Naciones Unidas sobre Derechos del Niño para construir un argumento interesante relativo a la patria potestad, en el cual se busca permitir e incluso asegurar la convivencia de un menor de edad con sus padres, protegiendo su interés superior, en tanto no haya razones que justifiquen la restricción o que lo pongan en riesgo.

\section{5. $1624 / 2008$}

En este asunto se impugnó originalmente, por medio del amparo, la sentencia del Segundo Tribunal Unitario del Décimo Tercer Circuito, donde se señala que ni el juez de primera instancia ni la autoridad responsable tomaron en consideración la especificidad cultural del quejoso y que posteriormente el Tribunal Colegiado había interpretado de manera restrictiva el derecho de los individuos a auto adscribirse o auto identificarse como indígenas, consagrado en el artículo 2o., párrafo tercero, de la Constitución Federal.

La Suprema Corte, para establecer la categoría "persona indígena" contemplada en el artículo 2o. constitucional, utiliza el Convenio 169 de la Organización Internacional del Trabajo, así como el contenido de 
la Declaración de las Naciones Unidas sobre los derechos de los pueblos indígenas, aprobada por la Asamblea General de este organismo el 13 de septiembre de 2007. Asimismo, se apoya en lo establecido por la Corte Interamericana de Derechos Humanos en los casos de la Comunidad Mayagna (Sumo) Awas Tingni; el de la Comunidad Indigena Sawhoyamaxa; el de la Comunidad Indigena Yakye Axa; y el del Pueblo Saramaka.

Para establecer la forma en que se deben considerar las costumbres y especificidades culturales de los indígenas en juicios y procedimientos, la Suprema Corte se apoya en lo establecido por el Comité para la Eliminación de la Discriminación Racial de las Naciones Unidas en su recomendación general número 23, lo señalado por la Comisión Interamericana de Derechos Humanos en la Resolución sobre la "Protección Especial de las Poblaciones Indígenas, Acción para Combatir el Racismo y la Discriminación Racial" y en su Informe sobre la situación de los derechos humanos en Ecuador de 1997. De igual manera, utiliza lo establecido por la Corte Europea de Derechos Humanos en el caso Connors y los antes citados de la Corte Interamericana de Derechos Humanos. En esta sentencia se acude incluso a lo establecido por la Comisión Africana sobre Derechos Humanos y de los Pueblos en el caso The Social and Economic Rights Action Center and the Center for Economic and Social Rights.

\section{6. $75 / 2009$}

En el amparo se impugnó la constitucionalidad de los artículos 1o., 2o. y 14 de la Ley Federal de Responsabilidad Patrimonial del Estado, por establecerse en la última disposición un límite máximo a la indemnización que por daño moral debe pagar el Estado. La Suprema Corte en la parte final del considerando quinto, y a mayor abundamiento, señala como ese límite podría generar el incumplimiento de obligaciones internacionales ya que esa ley, según se establece en su artículo 2o., párrafo segundo, sirve para cumplimentar las recomendaciones y los fallos de la Comisión y Corte Interamericana de Derechos Humanos, respectivamente.

Para establecer lo anterior, el máximo tribunal acude a los criterios que la Corte Interamericana ha establecido respecto a la naturaleza y alcances de la obligación de reparar, y dentro de éstos el concepto de daño inmaterial y los supuestos en que corresponde indemnizarlo, destacando que en ningún caso ha fijado un límite mínimo ni máximo para su 
otorgamiento, según se ha establecido en los casos Velásquez Rodríguez, Ticona Estrada y otros, Valle Jaramillo y otros, Tristán Donoso, Los "niños de la calle" (Villagrán Morales y otros), Ivcher Bronstein, Baena Ricardo y otros, Tribunal Constitucional, Blake, Castillo Páez, Garrido y Baigorria, Apitz Barbera y otros ("Corte Primera de lo Contencioso Administrativo") y Heliodoro Portugal, en sus sentencias de reparaciones o al referirse al artículo 63.1 de la Convención Americana. Asimismo se acude a lo señalado por la Corte Permanente de Justicia Internacional en el caso Chorzów.

En el caso destaca igualmente que la Suprema Corte señala que:

En este sentido, el párrafo segundo, de la fracción II, del artículo 14 de la Ley Federal de Responsabilidad Patrimonial del Estado, es tanto contraria al derecho de origen nacional (artículos 113), como al derecho de origen internacional (artículo 63.1 de la Convención Americana sobre Derechos Humanos).

Podríamos afirmar que se trata del primer asunto en el que la Suprema Corte de Justicia de la Nación hace un control de "convencionalidad" directo, tal vez un poco velado, pero ya un primer intento al tener frente a sí una disposición que de manera clara podría ir en contra de las obligaciones internacionales adquiridas por el Estado mexicano.

\section{7. $2044 / 08$}

En este asunto el quejoso denunciaba la inconstitucionalidad de los artículos 10., 3o., 4o., 5o. y 6o. de la Ley de Imprenta del Estado de Guanajuato, por estimarlos contrarios a los artículos 6o. y 7o. de la Constitución Federal. En la sentencia, con el fin de establecer los alcances a la libertad de expresión frente a la vida privada de los funcionarios públicos, así como el alcance y restricciones de los dos derechos, se acude a lo establecido por el Comité de Derechos Económicos, Sociales y Culturales en sus observaciones generales 4, 7 y 14; y al Comité de Derechos Humanos en sus observaciones generales 16 y 28. De la Corte Interamericana de Derechos Humanos se utilizan criterios fijados en los casos Tristán Donoso, Herrera Ulloa, Ivcher Bronstein, La "última tentación de Cristo" (Olmedo Bustos y otros), Kimel, Palamara Iribarne, Ricardo Canese, Claude Reyes y otros; así como en su opinión consultiva 
OC-5/85 y la resolución de las medidas provisionales del periódico $L a$ Nación.

La Comisión Interamericana aporta lo dicho en el caso 11.006, informe número 1/95; y el capítulo III del Informe Anual sobre Libertad de Expresión 2008, elaborado por la Relatoría Especial para la Libertad de Expresión. De la Corte Europea de Derechos Humanos los casos Thoma, Feldek, Sürek y Özdemir, Dichand y otros, y el caso Lingens. En cuanto a normas, se acude esencialmente al contenido del artículo 13 de la Convención Americana sobre Derechos Humanos e indirectamente al artículo 17 del Pacto Internacional de Derechos Civiles y Políticos y al artículo 12 de la Declaración Universal de los Derechos Humanos.

\section{AMPAROS EN REVISIÓN}

\section{1. $287 / 2007$}

En la demanda de amparo se impugnó el artículo 28 de la Ley Federal de Procedimiento Contencioso Administrativo. En el considerando quinto de esta sentencia se utiliza por una parte lo establecido por la Corte Interamericana de Derechos Humanos en su opinión consultiva OC-9/87 "Garantías judiciales en estados de emergencia (artículos 27.2, 25 y 8o. de la Convención Americana sobre Derechos Humanos), respecto a la efectividad de los recursos prevista en el artículo 25 de la Convención Americana, para a partir de ello, establecer si el derecho a la tutela judicial se veía afectado por la norma impugnada. Por otra parte, en esa misma sentencia se utiliza lo establecido por el Tribunal Interamericano en los casos Genie Lacayo, Comunidad Indigena Yakye Axa, Hermanas Serrano Cruz, Tibi, Ricardo Canese, y la "Masacre de Mapiripán", respecto a la razonabilidad del plazo para resolver un caso, En donde se destaca de manera particular la actividad procesal del interesado, esto con el fin de demostrar si en ese sentido se veía afectado el derecho del quejoso.

\section{2. $514 / 2007$}

En este caso se presentó el amparo en contra de la negativa de la libertad preparatoria por prohibición expresa de la ley (artículo 85, frac- 
ción I, inciso j) prevista en el Código Penal Federal. La Suprema Corte de Justicia de la Nación, para analizar si se veía afectado el derecho a la igualdad, en primer lugar establece en el considerando sexto de la sentencia los instrumentos internacionales en donde se encuentra reconocido el principio de la protección igualitaria y efectiva de la ley y de la no discriminación .

Posteriormente, y para fortalecer su argumentación respecto al derecho a la igualdad, cita lo establecido por la Corte Interamericana de Derechos Humanos en la opinión consultiva OC-4/84, "Propuesta de modificación a la Constitución Política de Costa Rica relacionada con la naturalización”, y la opinión consultiva OC-17/02 "Condición jurídica y derechos humanos del niño. Así como lo establecido por la Corte Europea de Derechos Humanos en los casos Willis, Wessels-Bergervoet, Petrovic $y$ "relating to certain aspects of the laws on the use of languages in education in Belgium "; lo señalado por la Comisión Interamericana de Derechos Humanos en los casos Marzioni, Marín Ramírez y Aylwin Azócar; lo expresado por la Comisión Africana sobre Derechos Humanos y de los Pueblos en el caso Legal Resources Foundation, y lo establecido por el Comité de Derechos Humanos de Naciones Unidas en el caso De Groot.

Con todo lo anterior, la Suprema Corte concluye que:

... resulta evidente que las interpretaciones dadas a los artículos de los tratados internacionales que consagran la igualdad y no discriminación, son enteramente compatibles con las interpretaciones dadas por este Alto Tribunal al artículo 1o., tercer párrafo de la Constitución Política de los Estados Unidos Mexicanos, mismas que fueron desarrolladas en la sentencia que ahora se revisa.

\section{3. $715 / 2007$}

En esta sentencia se analiza si el artículo 30 de la Ley Federal de Responsabilidades Administrativas de los Servidores Públicos es contrario al artículo 16 constitucional y al artículo 8.1 de la Convención Americana sobre Derechos Humanos. Para resolver la litis la Suprema Corte acude a lo establecido por la Corte Interamericana de Derechos Humanos en la opinión consultiva OC-9/87, "Garantías judiciales en estados de emergencia" (artículos 27.2, 25 y 8o. de la Convención Americana 
sobre Derechos Humanos), así como en los casos Tribunal Constitucional y Baena Ricardo. También utiliza lo señalado por la Corte Europea en los casos Albert and Le Compte, Campbell and Fell, Deweer y Angel and others, para establecer que el artículo impugnado no contraviene las normas que se consideraban violadas al prever que la ejecución de las sanciones administrativas se lleve a cabo de inmediato.

Por otra parte y para apoyar la anterior conclusión utiliza lo establecido por la Corte Interamericana de Derechos Humanos en los casos Genie Lacayo, Suárez Rosero, Comunidad Moiwana, Hermanas Serrano Cruz, Tibi y "Masacre de Mapiripán", así como algunas decisiones de la Corte Europea para establecer lo que se entiende o lo que comprende el plazo razonable.

\section{4. $976 / 2007$}

El recurso se interpuso en contra de una sentencia de amparo que resolvió respecto a la constitucionalidad del artículo 31 bis, segundo párrafo, de la Ley Federal de Competencia Económica. En la sentencia para establecer en dónde o ante qué actos se debe observar el debido proceso se acude a lo señalado por la Corte Interamericana de Derechos Humanos en el caso del Tribunal Constitucional y la opinión consultiva OC-9/87, ya citada. También hace referencia a lo expresado por la Corte Europea en los casos Campbell and Fell, Albert and Le Compte, Deweer y Angel and others. Con todos esos referentes, la Suprema Corte concluye que de acuerdo con los precedentes sustentados por ella, así como los de los órganos internacionales que cita, se puede establecer que la nota distintiva para determinar cuáles son los procedimientos que deben cumplir con la garantía de audiencia la da el hecho de que aquéllos concluyan con una resolución que pueda privar o establecer derechos sustantivos, privar la libertad personal, las propiedades o posesiones de los gobernados.

\section{5. $1099 / 2007$}

En este recurso se impugnó el artículo 41 del Código Federal de Procedimientos Penales por considerarlo contrario a los artículos 14 y 16 de la Constitución Federal. En la sentencia, la Suprema Corte acude a la jurisprudencia de órganos internacionales para señalar que la inter- 
pretación que hace de la compatibilidad del artículo impugnado con la Constitución también es acorde con los estándares internacionales y con el derecho de origen internacional. En primer lugar se hace referencia a lo establecido en los artículos 80. y 25 de la Convención Americana sobre Derechos Humanos y 14 del Pacto Internacional de Derechos Civiles y Políticos. En segundo lugar, y para establecer que, por arbitrario que se pueda considerar el desechamiento de plano de promociones improcedentes, sí se señala por la propia legislación un control judicial contra ello, se cumple con los estándares internacionales en materia de derechos humanos, se acude a lo señalado por la Corte Interamericana de Derechos Humanos en su opinión consultiva OC-9/87, antes citada.

\section{6. $173 / 2008$}

En este asunto se impugnó el artículo 271, segundo párrafo, de la Ley General de Salud y se hace un interesante análisis y desarrollo de los límites entre el derecho al trabajo de los médicos y el derecho a la salud de los pacientes.

Para un primer análisis de las restricciones válidas a los derechos humanos, en la sentencia se acude a lo establecido por la Corte Europea en los casos Barthold y The Sunday Times, igualmente lo señalado por la Corte Interamericana de Derechos Humanos en la opinión consultiva OC-5/85 del 13 de noviembre de 1985, "La colegiación obligatoria de periodistas" (artículos 13 y 29 de la Convención Americana sobre Derechos Humanos).

Ante el poco desarrollo jurisprudencial del derecho a la salud en México, para definir el contenido de este derecho se acude en un primer momento al contenido de los artículos 25, párrafo primero, de la Declaración Universal de Derechos Humanos; 12 del Pacto Internacional de Derechos Económicos, Sociales y Culturales; 10 del Protocolo Adicional a la Convención Americana sobre Derechos Humanos en materia de Derechos Económicos, Sociales y Culturales, "Protocolo de San Salvador"; lo establecido por la Comisión de Derechos Humanos en su resolución 1989/11, así como también en la Declaración y Programa de Acción de Viena de 1993 y en otros instrumentos internacionales. En un segundo momento acude a lo señalado por el Comité de Derechos Económicos, Sociales y Culturales de las Naciones Unidas en su observación general 
número 14, así como por la Corte Interamericana de Derechos Humanos en los casos Ximenes Lopes y Albán Cornejo y otros.

Parte interesante del asunto es que muchos de los argumentos se construyen justamente al utilizar el derecho de origen internacional con el derecho de origen nacional respecto a restricciones válidas a derechos humanos, derecho al trabajo y derecho a la salud. Asimismo, destaca que de este asunto derivaron varias tesis que se han convertido en jurisprudencia, de entre las que destaca por su contenido e importancia que le da al derecho de origen internacional la siguiente: "Derecho a la salud. su regulación en el artículo 4o. de la Constitución Política de los Estados Unidos Mexicanos y su complementariedad con los tratados internacionales en materia de derechos humanos".

\section{6. $220 / 2008$}

En este asunto se impugnó la Ley del ISSSTE. La Suprema Corte a mayor abundamiento y para fortalecer sus argumentos señala la compatibilidad de dicha Ley con lo establecido en la Declaración Universal de Derechos Humanos (artículos 22 y 25); en el Pacto Internacional de Derechos Civiles y Políticos (artículos 9o., 10.2 10.3); en la Declaración Americana de los Derechos y Deberes del Hombre (artículo XVI); en la Convención Americana sobre Derechos Humanos (artículo 26); en el Protocolo de "San Salvador" en materia de Derechos Económicos, Sociales y Culturales (artículo 9o.) y de manera especializada en el Convenio número 102 de la Organización Internacional del Trabajo sobre la seguridad social (norma mínima); aunque en el desarrollo particular de esa compatibilidad se hace el análisis principalmente sólo respecto al Convenio de la OIT.

Al tratar sobre la progresividad de los Derechos Económicos, Sociales y Culturales, la Suprema Corte señala que la nueva Ley del ISSSTE no afecta dicho principio y que incluso satisface lo establecido en el artículo 26 de la Convención Americana sobre Derechos Humanos, el artículo 1o. del Protocolo de "San Salvador", adicional a dicha Convención, asimismo el artículo 2o. del Pacto Internacional de Derechos Económicos, Sociales y Culturales. 


\section{7. $619 / 2008$}

En el amparo se impugnó la resolución emitida en la causa penal número 206/2004-II-2, radicado en el Juzgado Tercero de Distrito en el Estado de Chiapas, instruida en contra de la quejosa por su probable responsabilidad en la comisión del delito contra la salud, en la modalidad de transporte de clorhidrato de cocaína, previsto en el artículo 194, fracción I, del Código Penal Federal.

En la sentencia para establecer aspectos relativos al acceso a la justicia, de tutela jurisdiccional efectiva, plazo razonable y a una defensa adecuada se acude a lo establecido por el Comité de Derechos Humanos en sus observaciones generales 31 y 32, así como el caso Henry. De la Corte Interamericana de Derechos Humanos en su opinión consultiva OC-11/90; de igual manera en los casos Velásquez Rodríguez, Godínez Cruz, "La última tentación de Cristo" (Olmedo Bustos y otros), La Cantuta, Zambrano Vélez Tibi y otros, Garrido y Baigorria, Castañeda Gutman, Suárez Rosero, Juan Humberto Sánchez, Hilaire, Constantine, Benjamin y otros, y Valle Jaramillo.

\section{44/2009}

Esta sentencia se emitió con motivo de la facultad de atracción $33 / 2008$, la cual más adelante se detallará. El amparo había sido interpuesto en contra del artículo 6o., del Reglamento para los Servicios Médicos del ISSSTESON, y en la sentencia para determinar si dicha disposición era contraria a la Constitución, se utilizan casi en su totalidad las normas y estándares internacionales que habían sido sugeridos en la facultad de atracción, tales como: los artículos 22 y 25 de la Declaración Universal de los Derechos Humanos; 16 de la Declaración Americana de los Derechos y Deberes del Hombre; 9o. del Pacto Internacional de Derechos Económicos, Sociales y Culturales, y 9o. del Protocolo Adicional a la Convención Americana sobre Derechos Humanos en Materia de Derechos Económicos, Sociales y Culturales, así como lo expresado por el Comité de Derechos Económicos Sociales y Culturales, en sus observaciones generales 14 y 19 . 


\section{9. $460 / 2008$}

El amparo fue promovido porque el quejoso consideraba que el artículo 388 del Código de Procedimientos Penales del Estado de Chihuahua, al no permitir que las sentencias que se sigan por delito sancionado con pena máxima de 4 años de prisión sean recurribles o impugnadas, era contrario a los artículos 14, 16 y 20 de la Constitución, del mismo modo a los tratados internacionales de derechos humanos.

En el dictamen para llegar a las conclusiones de que toda sentencia debe ser revisada y más si se trata del establecimiento de una sanción penal, así como que no era inconstitucional la norma impugnada porque el juicio de amparo servía como esa segunda instancia, se acude a lo establecido en el artículo 10 de la Declaración Universal de los Derechos Humanos, al artículo 9o. del Pacto Internacional de Derechos Civiles y Políticos y al artículo 8o. de la Convención Americana sobre Derechos Humanos. De igual manera a los criterios fijados por la Comisión Interamericana en los casos 9850, Maqueda, Informe 74/90 y 11.137, La Tablada, Informe 55/97, e igualmente por la Corte Interamericana en los casos Herrera Ulloa, Castillo Petruzzi y otros, y Castañeda Gutman.

El asunto es interesante, porque en un voto particular se contra argumenta el porqué no se puede llegar a la conclusión de que el amparo es la segunda instancia válida para los procesos penales. En el voto se dan una serie de razones por las cuales se considera que se hizo una incorrecta utilización de los criterios antes referidos. De igual manera, usando esos mismos criterios y normas de origen internacional, así como otros más novedosos, se dice cual debía ser la conclusión que mejor se ajusta a los estándares internacionales de derechos humanos y por qué.

\section{CONTRADICCIONES DE TESIS}

\section{$1.147 / 2006$}

La contradicción de tesis surgida entre dos tribunales colegiados de circuito tuvo como aspecto principal el estipular si en términos de lo dispuesto en el último párrafo del artículo 70 del Código Penal Federal, es procedente la sustitución de la pena de prisión impuesta cuando existe una sentencia ejecutoriada por delito doloso que se persigue de oficio 
dictada con posterioridad a la comisión del mismo por el que se juzga. Para resolver ese punto, la Suprema Corte se apoya en lo establecido por la Corte Europea en el caso Pélissier y Sassi, y por la Corte Interamericana de Derechos Humanos en los casos Suárez Rosero y Fermín Ramírez, utilizando el criterio relativo a que los requisitos de "razonabilidad, previsibilidad y proporcionalidad" se aplican no sólo a las medidas que afectan la libertad, sino también a las normas de derecho interno que autorizan la privación de libertad y los prerrequisitos esenciales para asegurar que los procedimientos penales sean justos.

\section{2. $160 / 2006$}

Esta contradicción de tesis entre las sustentadas por dos tribunales colegiados tiene como punto central si se cumple con la garantía de defensa adecuada prevista en el artículo 20, apartado A, fracción IX constitucional, cuando ante la inasistencia del defensor particular designado por el inculpado a la audiencia de vista en segunda instancia, se lleva a cabo la misma con la presencia del defensor público federal o de oficio, designado oficiosamente en el acto de la diligencia. Así, para definir lo que es defensa adecuada acude la Suprema Corte a lo establecido por el Tribunal Europeo de Derechos Humanos en los casos Kamasinski, Stanford y Tripoi; lo señalado por el Comité de Derechos Humanos de las Naciones Unidas en los casos Little, Collins, Trevor, Desmond Kenzie, Andrew Donner y Alphonso Tracey, Carol Baker, Dwight Fletcher y Anthony Rose, así como en la observación general número 13. De igual manera se utiliza lo señalado por la Corte Interamericana de Derechos Humanos en los casos Fermín Ramírez y Hilaire, Constantine y Benjamin y otros.

\section{3. $19 / 2008$}

La contradicción suscitada entre tres tribunales colegiados tenía como punto central a resolver si los adultos mayores que reclamen una pensión alimenticia de sus descendientes cuentan con la presunción de necesitarla o si les corresponde a ellos, como actores en el juicio de alimentos, demostrar esa necesidad. Si bien en esta sentencia no se utiliza jurisprudencia de órganos internacionales de protección a los derechos humanos, sí se acude al contenido de los Principios de las Naciones Unidas a favor 
de las personas de edad, adoptado por la Asamblea General de las Naciones Unidas el 16 de diciembre de 1991 en la Resolución 46/91, la Declaración sobre los Derechos y Responsabilidades de las Personas de Edad adoptada por la Asamblea General de las Naciones Unidas de 1992 y a los debates y conclusiones en foros como la Asamblea Mundial del Envejecimiento en Viena en 1982, la Conferencia Mundial sobre Derechos Humanos en 1993 (de la que emanó la Declaración citada), la Conferencia Mundial sobre Población de El Cairo en 1994 y la Cumbre Mundial sobre Desarrollo Social de Copenhague en 1995 para desarrollar parte importante de la argumentación.

\section{FACULTAD DE ATRACCIÓN}

\section{1. $33 / 2008$}

Esta solicitud de ejercicio de la facultad de atracción buscaba que el amparo en revisión 186/2008, que se encontraba en trámite ante un tribunal colegiado, fuera del conocimiento de la Suprema Corte al tratarse de una posible afectación al derecho a la salud contemplada en el artículo 4o. y 123 de la Constitución por el contenido del artículo 6o. del Reglamento para los Servicios Médicos del ISSSTESON.

Para establecer la importancia y trascendencia que implicaban los supuestos necesarios para ejercer la facultad de atracción, la Suprema Corte señaló, entre otras cosas, que:

La Suprema Corte de Justicia habrá pues de abordar un planteamiento que es muy novedoso, en cuyo contexto analizará la vulneración de los artículos 1o., 4o. y 123 constitucionales, en complementariedad con lo dispuesto por el derecho de origen internacional aplicable al caso, tomando en cuenta lo que órganos internacionales de protección de los derechos humanos han establecido respecto a las obligaciones que los Estados tienen para hacer garantizar y respetar el derecho a la salud y a la seguridad social; además de que se asocia no sólo a cuestiones de atención médica para los trabajadores, sino al hecho de que la regulación jurídica del acceso de éstos a los servicios de salud trasciende no únicamente para los trabajadores al servicio del Estado, sino para toda persona.

Si bien en este asunto no se utiliza jurisprudencia de órganos internacionales, lo relevante es que en la sentencia se establece ya a que ins- 
trumentos internacionales, así como a que documentos se puede acudir cuando se resuelva el fondo del asunto, lo cual es de suma importancia pues de cierta forma garantiza que en el asunto se acuda al derecho internacional de los derechos humanos de manera complementaria al de origen nacional.

\section{2. $31 / 2009$ y $46 / 2009$}

En la primera facultad de atracción que se menciona se analizó si era posible conocer del amparo directo 153/2007. Para establecer si el tema satisfacía los requisitos de importancia y trascendencia respecto a la libertad de expresión y del derecho a la información, se pone de relieve lo que establece la Declaración Universal de los Derechos Humanos (artículos 12 y 19), el Pacto Internacional de Derechos Civiles y Políticos (artículos 17 y 19) y la Convención Americana sobre Derechos Humanos (artículos 11 y 13). Asimismo, se recomienda que en el estudio de fondo se acuda a dichas normas y a los criterios consolidados sobre los temas que se tocan en el amparo, vertidos en numerosos informes de la Comisión y en pronunciamientos importantes de la Corte Interamericana, entre los que destaca la opinión consultiva 5/85 sobre la colegiación obligatoria de periodistas y sentencias como las emitidas en los casos $L a$ "última tentación de Cristo", Ivcher Bronstein, Herrera Ulloa, Ricardo Canese, Palamara Iribarne, Claude Reyes, Kimel, o los recientes casos Tristán Donoso, Perozo y Ríos. De igual manera para desarrollar el tema relativo al derecho a la intimidad se recomienda que sea observado lo dicho por el Comité de Derechos Humanos en su observación general número 16.

Para destacar la importancia que estos criterios internacionales han ido adquiriendo, basta con señalar que de manera puntual en la sentencia se dice que:

...el pronunciamiento que puede emitir la Corte tendrá una relevancia inmediata en un contexto jurídico en el que la actuación de los tribunales mexicanos está reglada y puede ser inmediatamente contrastada con normas y estándares que son derecho vinculante en nuestro país...

En la segunda facultad de atracción aquí señalada se utilizaron prácticamente los mismos argumentos, toda vez que el amparo directo 
154/2007, del cual se pedía la atracción, estaba relacionado con el amparo antes referido, pues ambos tenían el mismo acto reclamado aunque lo combatían por motivos y argumentaciones muy diversas.

\section{IMPEDIMENTO}

\section{1. $2 / 2009$}

En este asunto una de las ministras integrantes de la Suprema Corte planteó su impedimento para conocer de una facultad de atracción, toda vez que dos de sus familiares forman parte de una persona moral que en calidad de quejosa solicitó el amparo respecto al cual se pretendía ejercer la facultad de atracción. En el considerando segundo de la sentencia como parte de la argumentación, se acude a lo establecido por el Comité de Derechos Humanos en el caso Karttunen, así como a lo señalado por la Comisión Interamericana de Derechos Humanos en el caso Martín de Mejía y la Corte Interamericana en el caso Apitz Barbera y otros ("Corte Primera de lo Contencioso Administrativo”) para establecer lo que implica y como puede entenderse la imparcialidad del juzgador.

De igual forma y para señalar qué aspectos deben ser tomados en cuenta para evaluar si un juzgador se encuentra impedido para conocer un asunto, se acude en la sentencia a lo establecido por la Comisión Interamericana en los casos Gómez López, Vila-Masot y Malary; por la Corte Europea de Derechos Humanos en el caso Daktaras, así como lo señalado por la Corte Interamericana de Derechos Humanos en el caso Apitz Barbera y otros.

\section{FACULTAD DE INVESTIGACIÓN}

\section{1. $3 / 2006$}

En este caso la investigación se llevó a cabo respecto de los hechos acaecidos el 3 y 4 de mayo de 2006 en los poblados de Texcoco y San Salvador Atenco, Estado de México.

En esta resolución se elaboró todo un apartado relativo a los criterios emitidos por órganos internacionales de protección a los derechos huma- 
nos en cuanto al uso de la fuerza. Así, se hace referencia a lo dicho por la Corte Europea de Derechos Humanos en los casos McCann y otros, Makaratzis y Mahmut Kaya. De la Corte Interamericana se citan los casos Neira Alegría y otros, Durand y Ugarte, Zambrano Vélez y otros, y Montero Aranguren y otros (Reten de Catia). En tanto que de la Comisión Interamericana de Derechos Humanos se menciona el caso 11.382, Finca "La exacta", informe 57/02.

De igual manera, se citan al menos 14 instrumentos internacionales de derechos humanos, que contienen disposiciones relativas al uso de la fuerza y otros que incluyen todos los derechos humanos.

Para el análisis de la violación al derecho a la vida se utilizan los criterios emitidos por el Comité de Derechos Humanos en su observación general número 6, así como lo dicho por la Corte Interamericana en los casos Masacre de Ituango, Los "niños de la calle”, Penal Miguel Castro Castro, Vargas Areco, Hermanas Serrano Cruz y Escué Zapata, entre otros. De la Corte Europea se utilizan los casos Mahmut Kaya, Osman y Kilic.

En el análisis del derecho a la integridad personal se utiliza el caso Loayza Tamayo de la Corte Interamericana y la observación general número 20 del Comité de Derechos Humanos. El derecho a la libertad personal es estudiado utilizando los casos Gangaram Panday y Suárez Rosero del Tribunal Interamericano, así como la observación general número 8 del Comité de Derechos Humanos. En cuanto al derecho a la justicia, así denominado en la resolución, se acude a lo establecido por la Corte Europea en los casos McCann, Kelly y otros, Assenov y otros y Aydin; de la Corte Interamericana los casos Penal Miguel Castro Castro y otros que se citan en esa sentencia. Finalmente, en el análisis de la libertad de expresión se hace referencia a la observación general número 10 del Comité de Derechos Humanos, así como a la opinión consultiva OC-5/85 y al caso La "última tentación de Cristo" (Olmedo Bustos y otros).

Estos casi 30 asuntos dan muestra de que el material de análisis se ha ampliado pese a que aún es reducido si lo comparamos con lo que hacen otros tribunales supremos y constitucionales de Latinoamérica.

Sin duda, un análisis profundo de todo lo anterior nos mostrará que no siempre la utilización del derecho de origen internacional ha sido del todo afortunada, por lo cual ese segundo nivel de análisis deberá ocuparse no sólo de las sentencias, sino también de los debates y la forma en que se llegó a ellas, así como de los antecedentes y el camino que se ha 
seguido para que, a partir de ello, se construya una más óptima utilización, aplicación $\mathrm{y}$, por qué no, control de los tratados internacionales y sus interpretaciones.

Los primeros pasos que han abierto el camino de la plena incorporación del derecho de origen internacional de los derechos humanos a las sentencias de la Suprema Corte de Justicia de la Nación, como observamos, ya se han dado tanto en las Salas como en el Pleno de ese tribunal. Ahora es momento de consolidarlos y de abrir un debate serio respecto a si la forma en la que se está haciendo es la más optima o si es necesario replantearnos con las herramientas que tenemos la manera en la cual se debe de llevar a cabo y hasta dónde se puede llegar. 